MATEC Web of Conferences 24, 09003

(2015)

DOI: $10.1051 /$ matecconf/20152409003

(C) Owned by the authors, published by EDP Sciences, 2015

\title{
INVESTIGATION OF TENSION FORCES IN A STAY CABLE SYSTEM OF A ROAD BRIDGE USING VIBRATION METHODS
}

\author{
Paweł Hawryszków ${ }^{1, a}$ \\ ${ }^{1}$ Wrocław University of Technology, Chair of Bridges and Railways, Wybrzeże Wyspiańskiego 27, 50-370 Wrocław, Poland
}

\begin{abstract}
In the article author presents method of investigation of tension forces in stay cable systems using dynamical methods. Research was carried out during stay cable system installation on WN-24 viaduct near Poznań, that is way it was possible to compare tension forces indicated directly by devices using for tensioning of cable-stayed bridges with results achieved indirectly by means of dynamical methods. Discussion of results was presented. Advantages of dynamical methods and possible fields of application was described. This method, which has been rarely used before, may occur interesting alternative in diagnostics of bridges in comparison to traditional methods.
\end{abstract}

\section{Introduction}

The main structural elements of cable-stayed bridges are: stay cable system, deck and pylon. Taking into consideration the safety of cable stayed structures, stay cable systems require periodical inspections, including control of tension forces in cables. Such technical examinations are very important, because there is possibility of changes in forces configuration during exploitation of the structure, caused by for example: rheological phenomena in cables, settlement of supports (pylons), cable strands corrosion or their mechanical damages. Typical inspections are connected with necessity of interfering in anticorrosively proctected anchorage area, where strands are located, and also with measuring of cable tension forces using hydraulic jacks. In this paper the author introduces an alternative procedure for examination of tension forces in stay cable systems of cable-stayed bridges by using dynamical methods. Results of measurements carried out on bridge structure WN-24 over divided highway S5 near to Poznan (the Kleszczowo junction) are presented. Investigations were carried out by courtesy of companies Warbud (general contractor) and Freyssinet (subcontractor responsible for installation of stay cable system on considered structure).

\section{Investigation of stay cables system of WN-24 viaduct}

The viaduct $\mathrm{WN}-24$ is localized over S5 express road (Gniezno-Poznan), in resting area for travellers. It was designed as cable-stayed, two-span structure with single pylon type 'A'. The deck is composed of two

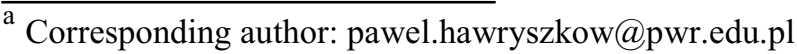

$80 \mathrm{~cm}$ high plain girders and $25 \mathrm{~cm}$ thick concrete slab. Plate girders are different height, connected with deck slab. The pylon was designed partly as conrete structure (from a foundation to a deck level) and partly as steel structure (the rest $25,12 \mathrm{~m}$ of its height). Theoretical length of the suspended span is $56,20 \mathrm{~m}$, and of the back span is $13,60 \mathrm{~m}$. Longer span is suspended to the pylon structure using 4 pairs of stays and the pylon is stabilized by 3 pairs of back stays. Some photos of the viaduct are presented on Fig. 1 and the geometry of the considered structure is illustrated on Fig. 2.

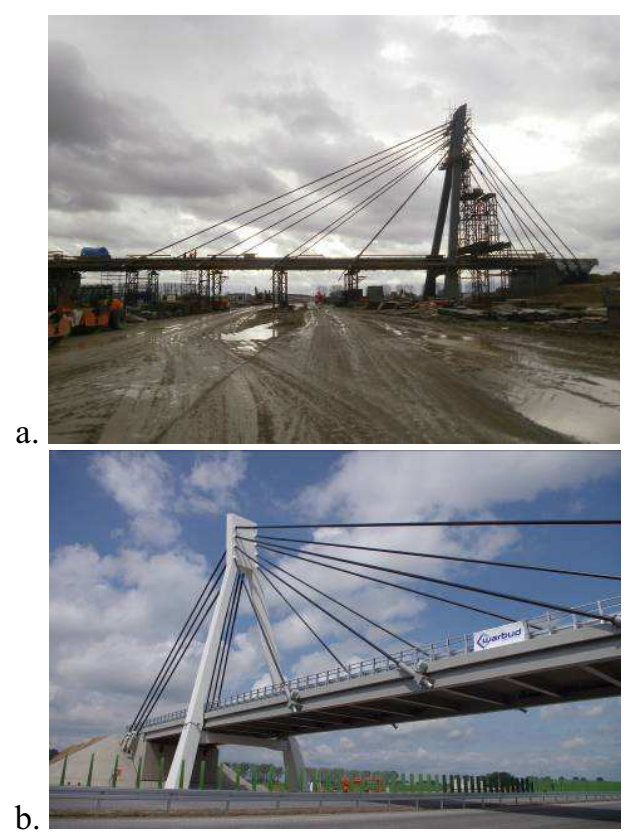

Figure 1. Overall images of the viaduct: a. construction phase and stage of dynamical tests, b. finished structure (archive of Warbud). 


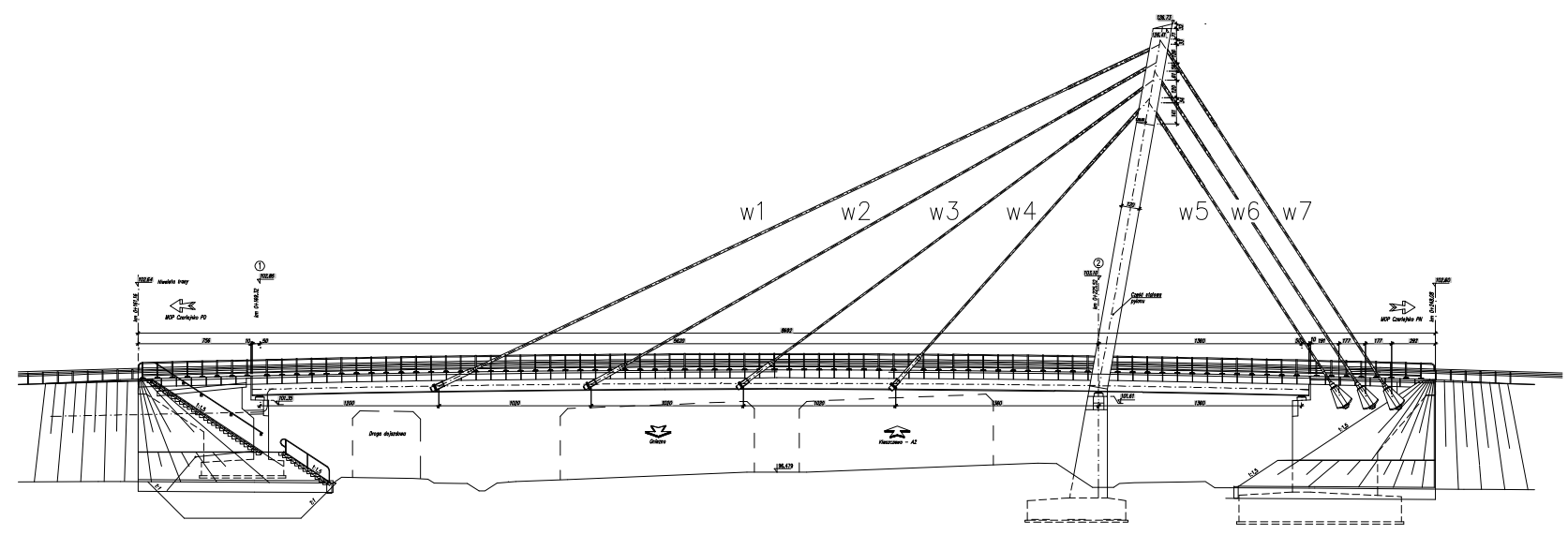

Figure 2. Side view of the structure with numeration of stay cables.

Measurements were carried out during installation of stay cable system, so it was possible to compare results obtained by dynamical methods with results received by devices used by contractors in installation process [1]. For measurements accelerometers were used, installed directly on stay cables (Fig. 3a). Sensors of forces were localized on the reference strand of a cable (Fig. 3b) during stay cable system installation phase. Measurements were performed for 7 stay cables from south side of the bridge, which are marked on Fig. 2.

a.

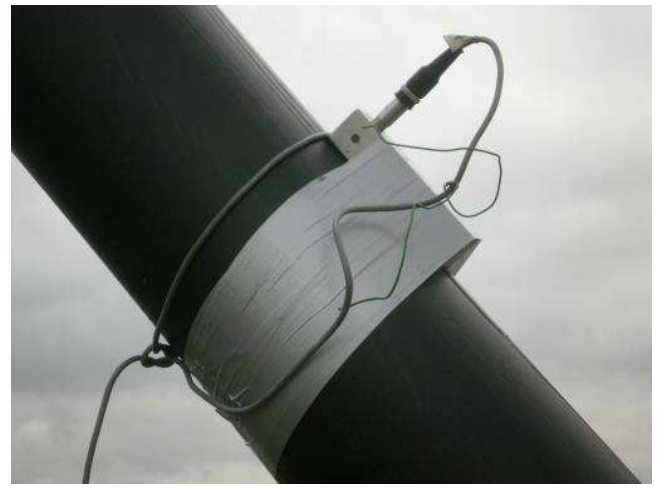

b.

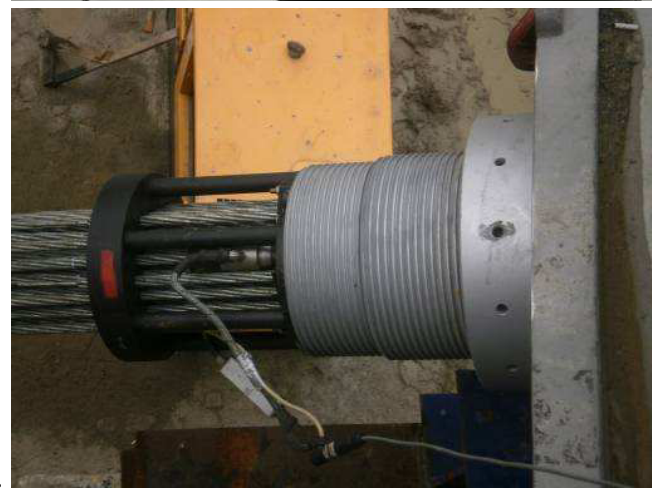

Figure 3. Measurement devices: a. accelerometer installed on external protecting HDPE tube (Hottinger Baldwin Messtechnik $\mathrm{GmbH}, \mathrm{B} 12 / 200)$, b. load cell installed on the reference strand (Freyssinet).

Results from both types of sensors were recorded parallelly on two computers (see Fig. 4). One computer was recording measurement of cable vibration and the second one was used to readout actual force value in the reference strand. Freyssinet company who realized a stay cable system in the considered bridge structure use 'Isotension' method [1], which allows to achieve the same values of tension forces in singular strands of cable, so force value in one strand multiplied by numbers of strands gives a value of tension force related to the whole cable.

a.

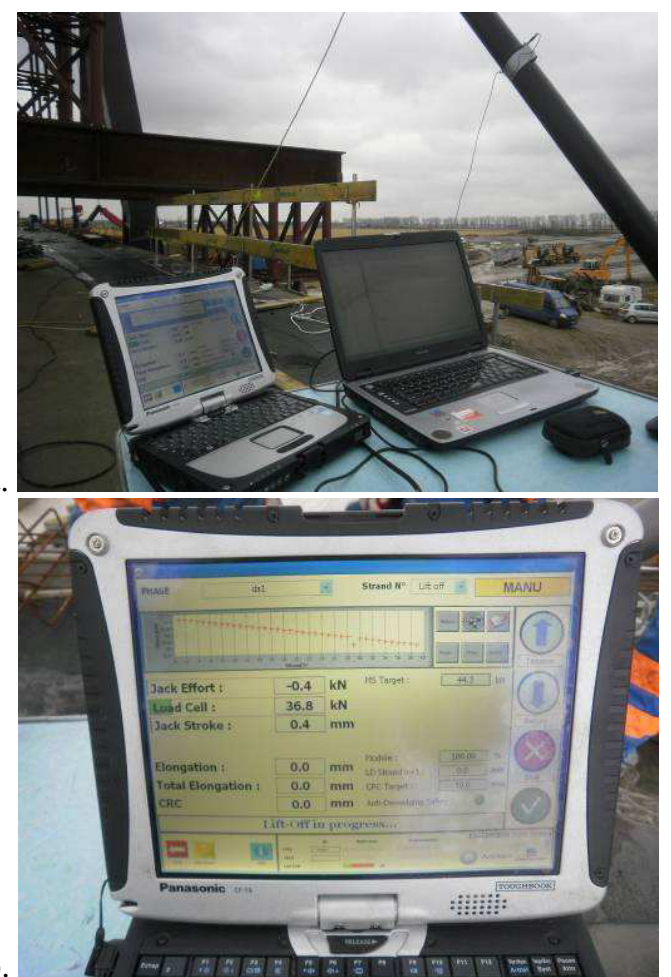

Figure 4. Recording devices: a. computers for controlling of tension forces and registration of vibrations, $b$. control of tension force in W2S stay cable (device and software of Freyssinet).

The main principle of dynamical measurements is based on the dependence between a force in a cable, length of a stay, distributed mass of the cable and frequency of its vibrations, according to given formula [2]: 


$$
f_{i}=\frac{i}{2 L} \sqrt{\frac{S}{m}}
$$

where $f_{i}-i^{\text {th }}$ vibrations frequency [Hz], $S-$ cable tension force $[\mathrm{N}], m-$ unit mass of a cable $[\mathrm{kg} / \mathrm{m}], L-$ cable length [m]. After a simple transformation the tension force is defined by following formula:

$$
S=4 m L^{2}\left(\frac{f_{i}}{i}\right)^{2} .
$$

A knowledge of fundamental data about an analyzed cable such as its length and unit mass, and also ability of determining vibration frequencies of stay cable allows to calculate tension force in cable. An example of recorded vibration signal of cable W2S (stay cable marked as W2 from the south side of the structure) together with its Fourier transform are presented on Fig. 5. For cables vibrations excitation an impulse excitation was initiated in a form of a single dynamical pre-tension of a rope which was fixed on a external protecting HDPE tube (pull). Wind-induced vibrations were also recorded during tests.
Selected data essential for analyse are given in Tab. 1: lengths ( $L$-according to geodetic measurements assumed as nodes of stay cables fixing points), masses of bundle of strands $\left(m_{\text {strands }}\right)$ and external protecting HDPE tubes $\left(m_{\mathrm{HDPE}}\right)$, total distributed mass of a cable $(m)$ and fundamental vibrations frequencies determined experimentally $\left(f_{\text {measured }}\right)$. These data were used for determining tension forces of particular cables $\left(S_{\mathrm{dyn}}\right)$ in accordance with formula (2). Tab. 2 contains also values of tension forces in reference strands $\left(S_{\text {strand }}\right)$, red out from tension force controlling devices, and following general tension forces in cables $\left(S_{\text {cable }}\right)$. The comparison of obtained results is presented in Tab. 1, as well.

Results presented in Tab. 1 show that in typical case it is possible to determine the tension force in cable with $95 \%$ reliability (difference in results does not exceed $5 \%$ ). The case of stay cables marked W1S and W3S should be treated as large error, which could be due to: not properly calibrated tension force controlling devices installed on reference strands,

- dynamical measurements carried out with usage of sensors installed on the protecting HDPE tube instead of directly on bundle of tensioned strands (in case of HDPE tubes that are not totally filled up with strands it may have influence on obtained results), coincidence of both above mentioned reasons.
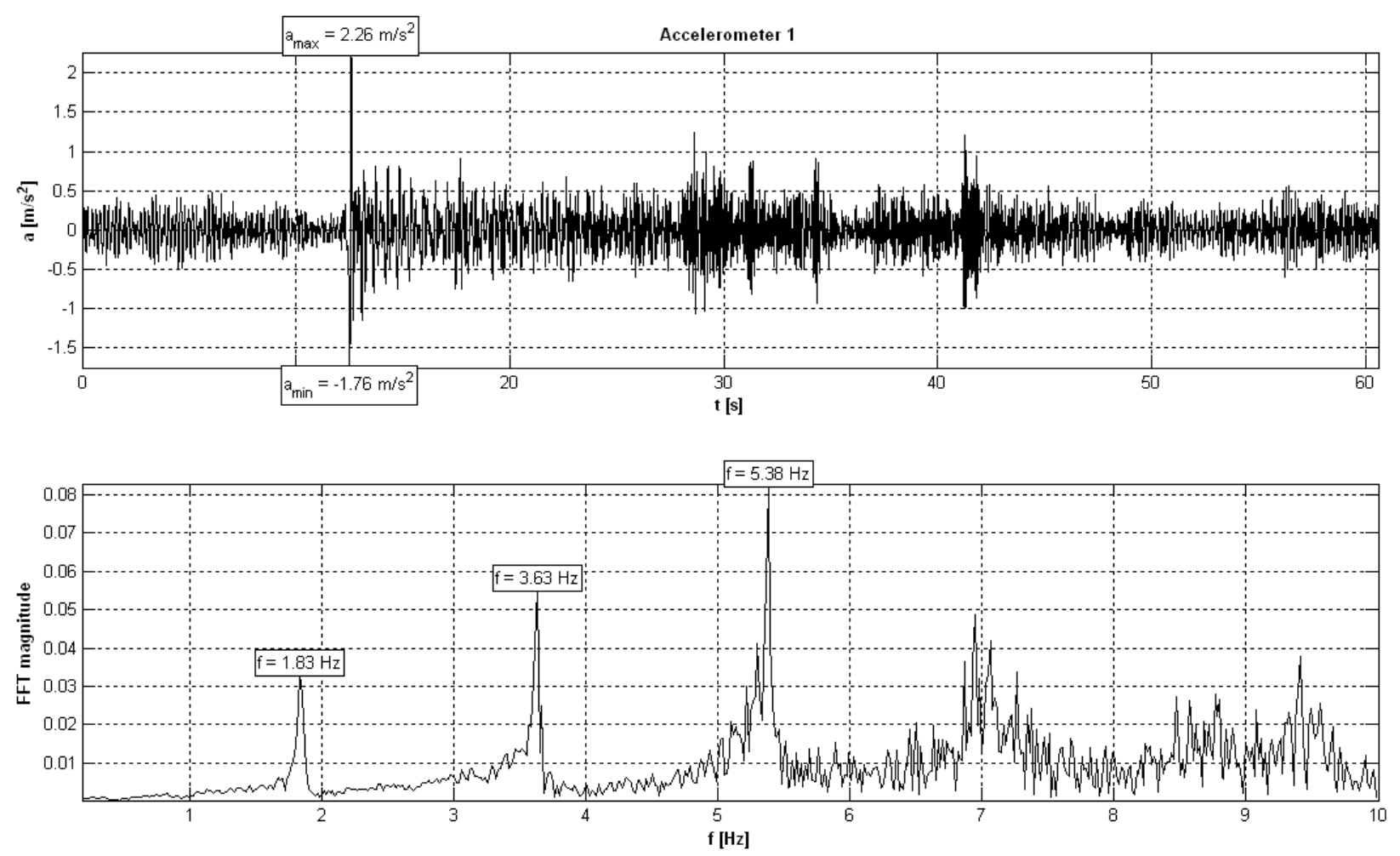

Figure 5. Signal of vibrations acceleration of W2S stay cable with Fourier transform. 
Table 1. Input data and results of analyses of tension forces in stay cables.

\begin{tabular}{|l|c|c|c|c|c|c|c|}
\hline Stay cable & W1S & W2S & W3S & W4S & W5S & W6S & W7S \\
\hline No. of strands & 39 & 32 & 25 & 25 & 32 & 32 & 32 \\
\hline$L[\mathrm{~m}]$ & 54.32 & 44.51 & 35.17 & 26.79 & 25.23 & 27.75 & 30.27 \\
\hline$m_{\text {strands }}[\mathrm{kg} / \mathrm{m}]$ & 50.7 & 41.6 & 32.5 & 32.5 & 41.6 & 41.6 & 41.6 \\
\hline$m_{\text {HDPE }}[\mathrm{kg} / \mathrm{m}]$ & 3.71 & 3.13 & 2.77 & 2.77 & 3.13 & 3.13 & 3.13 \\
\hline$m[\mathrm{~kg} / \mathrm{m}]$ & 54.4 & 44.7 & 35.3 & 35.3 & 44.7 & 44.7 & 44.7 \\
\hline$S_{\text {strand }}[\mathrm{kN}]$ & 34.8 & 36.8 & 22.6 & 19.7 & 44.1 & 44.3 & 39.5 \\
\hline$S_{\text {cable }}[\mathrm{kN}]$ & 1357 & 1178 & 565 & 493 & 1411 & 1418 & 1264 \\
\hline$f_{\text {mea sured }}[\mathrm{Hz}]$ & 1.52 & 1.83 & 1.98 & 2.26 & 3.48 & 3.28 & 2.85 \\
\hline$S_{\text {dyn }}[\mathrm{Hz}]$ & 1484 & 1187 & 684 & 517 & 1379 & 1482 & 1332 \\
\hline Difference $[\mathrm{kN}]$ & 126 & 9 & 119 & 25 & -32 & 65 & 68 \\
\hline Difference $[\%]$ & 9.3 & 0.8 & 21.1 & 5.0 & -2.3 & 4.6 & 5.3 \\
\hline
\end{tabular}

The measurements accuracy achieved in tests indicates, that the method may be useful in diagnostics of bridge structures. One should underline that dynamical measurements constitute an indirect method in relation to control of tension force in cable. Presented kind of tests belong to a group of non-destructive tests (similar as for example sclerometric methods developed for concrete strength examinations), and we can't expect the highest accuracy from them. In case of cables there are many factors, that may have influence on the final result as for example an effect of loose protecting HDPE tube, which was mentioned above. Also it may be an influence of an actual cable anchorage, which do not fulfil a theoretical model of a cable with a joint on its end (a basic assumption of formula (2)), and a problem of determining proper length of a cable in calculations, that is connected with cable structure. Moreover, tests were carried out insitu and some of contractor's devices were used here. In conditions specific for laboratory, where a process of tensioning can be fully controlled and where a less complicated model can be used, we may expect that results compatibility would be much better than in case of tested structure.

However, the main advantage of described method is not interfering in a stay cable system. In this method it is not necessary to disassemble a cover that protects a cable anchorage area and to expose stands by removing wax protecting layer. As a result of both these actions moisture may get inside an anchorage area and cause beginning of corrosion process. Moreover, the method do not require special hydraulic devices for controlling tension force in a cable, that is usually carried out using a single-strand hydraulic jack to tense selected individual strands till the moment of pulling out wedge which anchors the strand in the anchorage (destructing process).

In contradiction to described above procedure of cable tension controlling, the dynamical method requires only 'light' devices, which are installed on a suspension cable form the deck level (it is not necessary to use elevators in order to work in the area of cables anchorage under a deck or on a pylon). This unquestionable advantage results in a financial aspect of tension controlling process. The application of the method may by as follows:
- periodical monitoring of tension forces in cables in relation to cable-stayed bridges, which are not equipped with special monitoring systems,

- diagnostic of cables' tension forces in controlling process after realization.

The method in above mentioned range was implemented by the author in relation to a footbridge made of glue-laminated wood with a record-breaking length of suspended span, which is localized in Sromowce Niżne [3, 4].

\section{Summary}

The dynamical investigation method of stay cables which is known from bibliography, is described in this article [5]. In-situ measurements were carried out during installation of stay cable system of the viaduct $\mathrm{WN}-24$. Thanks to that it was possible to compare values of tension forces recorded directly by devices used by contractors of cable stayed bridges with values obtained by indirect way, on the basis of dynamical measurements. Results has been brought up for discussion. Advantages of dynamical methods and possible fields of their application in investigation of cable stayed bridges has been indicated. Presented method, which has been rarely used in practice so far, may occur to be an interesting alternative in a diagnostics of bridge structures in relation to traditional methods.

\section{References}

1. Hawryszków P., Hildebrand M.: Installation of the largest stay cable system in Poland - the Rędziński bridge in Wrocław. Proceedings of $18^{\text {th }}$ IABSE Congress "Innovative Infrastructures - Toward Human Urbanism”. Seoul, Korea, September 19-21, 2012,

2. Biliszczuk J. „Mosty podwieszone. Projektowanie i realizacja", Arkady, Warszawa 2005,

3. Hawryszków P.: Dynamic testing of cable-stayed footbridge with glued-laminated wooden main beams. EVACES'07, Experimental Vibration 
Analysis for Civil Engineering Structures, 24-26 October 2007, Porto, Portugal,

4. Biliszczuk J., Hawryszków P., Maury A., Sułkowski M., Węgrzyniak M.: A cable-stayed footbridge made of glued-laminated wood - design, erection and experimental investigations. IABSE Symposium, Weimar 2007, Sept 19-21,

5. Caetano E.: Cable vibrations in cable-stayed bridges. International Association for Bridge and Structural Engineering, Structural Engineering Documents, vol. $9 / 2007$. 